\title{
Compostagem AERóbia CONJUGADA DE LODO DE TANQUE SÉPTICO E RESÍDUOS SÓLIDOS VEGETAIS
}

\section{CONJUGATED AEROBIC COMPOSTING OF SEPTIC TANK SLUDGE AND VEGETABLE SOLID WASTE}

\begin{abstract}
ANDRE GUSTAVO DA SILVA
Biólogo. Mestre em Desenvolvimento e Meio Ambiente - PRODEMAUFPB/UEPB. Consultor Ambiental da Lógica
Engenharia ETE-TIP/Recife-PE e Professor da Escola Técnica Regional/Recife-PE
VALDERÍ DUARTE LEITE

Engenheiro Químico. Doutor em Hidráulica e Saneamento - EESC/USP. Professor do Departamento de Química da Universidade Estadual da Paraíba

\section{Mônica Maria Pereira da Silva}

Bióloga. Mestre em Desenvolvimento e Meio Ambiente - PRODEMAUFPB/UEPB. Doutoranda em Recursos Naturais/UFCG. Professora do Departamento de Biologia/UEPB

\section{SHIVA PRASAD}

Bacharel em Química. Doutor em Química. Professor do DEQ/CCT/UFCG

WANDERSON BARBOSA DA SiLVA FEITOSA

Graduando em Química Industrial/UEPB. Bolsista de PIBIC/CNPq/UEPB

Recebido: 14/06/07 Aceito: 03/06/08
\end{abstract}

\section{RESUMO}

O lodo sanitário, principal subproduto do tratamento de esgotos, constitui um dos maiores problemas ambientais urbanos da atualidade. Em meio a este contexto, objetivou-se nesse estudo avaliar o processo da compostagem conjugada de lodo de tanque séptico (LS) e resíduos sólidos vegetais (RV) e determinar a importância da temperatura para o processo de sanitização do substrato tratado. O experimento, inteiramente casualizado com três tratamentos e três repetições, consistiu de nove reatores aeróbios com 100 litros de capacidade. Os resíduos foram utilizados nas seguintes proporçōes - T1: $100 \%$ RV; T2: $5 \%$ LS + 95\% RV; T3: $10 \%$ LS + 90\% RV. A compostagem aeróbia conjugada mostrou ser uma alternativa viável para destruição de ovos de helminto e estabilização dos resíduos, sendo fundamentais para tal, a temperatura, o $\mathrm{pH}$ e as relaçôes ecológicas presentes nos reatores.

PALAVRAS-CHAVE: Compostagem, lodo de tanque séptico, resíduos sólidos vegetais, ovos de helmintos.

\begin{abstract}
The sanitary sludge, principal byproduct of sewage treatment, constitutes one of the major municipal environmental problems of the present time. The present study was aimed to evaluate the composting of septic tank sludge (SS) and vegetable solid waste $(V W)$ and to determine the importance of the temperature for the process of sanitization of the treated substrate. The experiment, entirely randomized with three treatments and three repetitions, constituted of nine aerobic reactors with $100 \mathrm{~L}$ capacity. The proportions of the wastes utilized were T1: 100\%VW; T2:5\%SS + 95\%VW; T3: $10 \% S S$ + 90\%VW. The conjugated composting showed to be a feasible alternative for destruction of helminth eggs and stabilization of the wastes. The temperature, $p H$ and ecological relations present in the reactors were fundamental for this purpose.
\end{abstract}

KEYWORDS: Composting, septic tank sludge, vegetable solid waste, helminth eggs.

\section{INTRODUÇÃO}

Segundo dados do IBGE (2000), de todo o quantitativo de resíduos sólidos produzidos no país, aproximadamente 50\% (percentagem em peso) é constituído por resíduos orgânicos putrescíveis, em sua maioria dispostos inadequadamente no meio ambiente, sendo responsáveis por prejuízos consideráveis ao solo, ar e mananciais hídricos, além de causar uma parcela significativa das doenças evitáveis registradas no nosso País.

Parte importante dos resíduos orgânicos urbanos, o lodo é o principal subproduto do tratamento dos esgotos sanitários (Silva, 2007), apresentando composição e propriedades bastante variáveis, dependendo da origem do esgoto e do processo de tratamento empregado, porém são tipicamente constituídos de materiais orgânicos e minerais, além de água e da presença 
de microrganismos patogênicos e elementos tóxicos.

No que tange aos lodos oriundos de tanques sépticos, especificamente, este são considerados lodo primário (Andreoli et al, 2001), por serem produtos de decantação primária, permanecendo no sistema por tempo suficiente para favorecer sua digestão anaeróbia em condiçôes controladas. Por sua vez, o lodo digerido é aquele que sofreu estabilização biológica (Nogueira, 2003).

Estudo conduzido por Chernicharo (1997), concluiu que o lodo de tanque séptico possui satisfatórias quantidades de macronutrientes, possibilitando a utilização do processo de compostagem.

Atualmente, a produção de lodo no Brasil está estimada entre 150 mil e 220 mil toneladas por ano. Devido aos baixos índices de coleta e tratamento de esgoto ainda existentes no país e à pressão da sociedade por melhores condiçôes ambientais, há uma potencial tendência de ocorrer um incremento substancial na quantidade de lodo a ser disposto nos próximos anos. Adiciona-se a isso o fato de que há uma utilização crescente, na maioria das vezes inadequada, deste resíduo em culturas agrícolas.

Portanto, urge que sejam apresentadas técnicas que possibilitem um tratamento eficiente e adequado de lodos sanitários, obedecendo aos critérios de baixo custo e a facilidade de operação e manutenção, consistindo, assim, em uma alternativa simplificada.

A compostagem aeróbia conjugada consiste, na visão de Silva (2007), no tratamento simultâneo de dois ou mais tipos de resíduos sólidos orgânicos com características físico-químicas que se complementam.

Os trabalhos que envolvem a compostagem conjugada de diferentes tipos de resíduos sólidos com lodo sanitário são pontuais e sem continuidade. No entanto, nos últimos anos, tem-se notado um crescente interesse por essa área de estudo, sobretudo do tratamento conjunto de lodos e resíduos industriais, devido à intenção de diminuir o índice de contaminação e a toxicidade desses últimos. A compostagem conjunta de lodo com resíduos orgânicos municipais é recente, por conta da percepção que muitos detêm sobre o lodo, acreditando que este contamina os resíduos, prejudicando a qualidade do composto resultante.
Muito embora, Klubber et al (2000) e Edlman et al (2000) constataram que a compostagem conjunta da fração orgânica de resíduos municipais com lodo, facilita o processo de decomposição desses resíduos, reduzindo em até 20\% o tempo necessário de tratamento.

Brito Jr. (2003), ao estudar a compostagem de lodo com resíduos vegetais, concluiu que o composto resultante se apresentou como um produto de excelente qualidade física, química e microbiológica, com amplas possibilidades para seu uso agronômico.

Nesse contexto, o aproveitamento integrado destes resíduos promoveria proteção à saúde pública, além da obtenção de um produto derivado com qualidade agronômica e livre de patógenos, para fins agrícolas.

Os ganhos em relação à adoção da compostagem envolvendo o lodo de esgoto vão além dos benefícios gerados à saúde humana e da sua utilização na agricultura. $\mathrm{O}$ meio ambiente é beneficiado na medida em que se evita o aporte de matéria orgânica nos sistemas aquáticos, mitigando, dessa forma, o processo de eutrofização antrópica.

Objetivou-se no presente trabalho, avaliar a eficiência do processo de compostagem aeróbia conjunta do lodo de tanque séptico (LS) e resíduos sólidos vegetais (RV); realizar as caracterizações física, química e biológica do LS e dos RV e avaliar a importância da temperatura para os processos de bioestabilização e sanitização do substrato tratado.

\section{MATERIAL E MÉTODOS}

O sistema experimental utilizado para a realização deste trabalho foi instalado e monitorado nas dependências externas da Estação Experimental de Tratamento Biológico de Esgotos Sanitários (EXTRABES), localizada na Cidade de Campina Grande/PB (7o 13' 11" Sul, 35० 52' 31" Oeste, a 500 metros acima do nível do mar), Estado da Paraíba, nordeste do Brasil. O período de realização do trabalho experimental foi de maio a setembro de 2006.

O sistema experimental foi do tipo inteiramente casualizado com três tratamentos e três repetiçôes, consistindo de nove reatores aeróbios com as seguintes referências - tipo de material: plástico rígido; forma geométrica: cilíndrica, altura: $63 \mathrm{~cm}$, diâmetro: $45 \mathrm{~cm}$ e capacidade volumétrica unitária: 100 litros. Os reatores foram previamente identificados pela letras "T" (tratamento) e "R" (repetição), seguidas dos numerais 1, 2 ou 3, fazendo alusão ao número do tratamento e sua respectiva repetição (Figura 1).

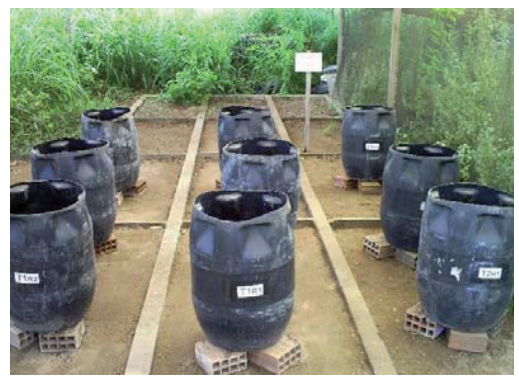

Figura I - Disposição dos reatores utilizados no experimento de compostagem aeróbia do lodo de tanque séptico e resíduos sólidos vegetais

O lodo foi retirado por meio de uma bomba de sucção manual de um tanque séptico unifamiliar que recebe esgotos domésticos há pelo menos 10 anos de uma família que é constituída de sete pessoas - três crianças, dois adultos e dois idosos. A residência está localizada a $13 \mathrm{~km}$ do centro da cidade de Campina Grande-PB, numa regiāo composta por pequenas propriedades situadas às margens da Alça Sudoeste, via de acesso a BR-230. A residência possui água encanada. $\mathrm{O}$ consumo mensal corresponde a $10 \mathrm{~m}^{3}$. A vazão diária chega a $0,33 \mathrm{~m}^{3} /$ dia e o tempo de detenção hidráulica (TDH) calculado nesse sistema foi de 4,36 dias ou 104,6 horas.

Os resíduos sólidos vegetais foram coletados manualmente, com o auxílio dos bolsistas e estagiários da EXTRABES, na Empresa Paraibana de Alimentos e Serviços Agrícolas (EMPASA) e na Feira Livre Central, ambos localizados da cidade de Campina Grande-PB. Após a coleta, estes resíduos foram acondicionados em sacos de nylon de $60 \mathrm{~kg}$ e transportados para o pátio de compostagem localizado nas dependências da EXTRABES, onde foram submetidos às seguintes operaçóes: trituração, com o objetivo de se obter a diminuição do tamanho das partículas da massa "in natura"; caracterização física, química e biológica; através das análises de $\mathrm{pH}$, teor de umidade, sólidos totais voláteis (STV), relação $\mathrm{C} / \mathrm{N}$ e ovos viáveis de helmintos e controle (ajustamento) do teor de umidade. 
Os resíduos foram misturados fazendo-se uso de pás e inchadas e, em seguida, colocados dentro dos reatores nas quantidades e percentuais descritos na Tabela 1.

A aeração do sistema ocorreu por reviramento manual periódico. No primeiro mês de duração, esse reviramento ocorreu três vezes por semana, nos meses subseqüentes, duas vezes a cada semana. Durante o revolvimento foram utilizados batas, luvas de lona emborrachadas até a altura dos ombros, óculos de segurança e respiradores com filtro.

A carga inicial e a composição do substrato (LS e RV) utilizado são apresentados na Tabela 1 .

Com objetivo de garantir que a amostra retirada fosse suficientemente representativa, foram coletadas amostras para análise dos parâmetros físico-químicos e biológicos retirando-se sub-amostras em 10 pontos diferentes dos reatores, sendo estas, em seguida, misturadas e quarteadas seguidas vezes até a retirada de uma única amostra em torno de $150 \mathrm{~g}$.

Os parâmetros monitorados foram: $\mathrm{pH}$, teor de umidade, sólidos totais voláteis (STV) e relação Carbono/Nitrogênio $(\mathrm{C} / \mathrm{N})$. Para as análises destes parâmetros seguiram-se as recomendações propostas em APHA (1998). As leituras diárias da temperatura foram feitas em cada um dos reatores em três pontos diferentes: topo, centro e base; fazendo-se uso de termômetro de haste de mercúrio (Incontel: $0-80^{\circ} \mathrm{C}$ ) sempre às 14:00 h. Para análises de ovos de helmintos, foram realizadas modificações ao método de Meyer (1978). A ausência de um método universalmente aceito de recuperação de ovos helmintos em resíduos sólidos motivou o teste de vários métodos Meyer, Yanko e Bailinger, todos citados por Soccol et al (2000); concluindo-se que Meyer (1978), com as devidas modificaçōes, permite a identificação de ovos nas diferentes fases do processo de codisposição, inclusive do composto resultante com eficiência de 95\%.

\section{RESULTADOS E DISCUSSÃO}

\section{Lodo de tanque séptico}

Os resultados advindos da caracterização física, química, e biológica do lodo de tanque séptico, após o período de secagem natural (ao sol), são apresentados na Tabela 2.

Tabela I - Quantidade e composição do substrato utilizado na compostagem

\begin{tabular}{ccc}
\hline Tratamentos & $\begin{array}{c}\text { Quantidade inicial de } \\
\text { substrato }(\mathrm{kg})\end{array}$ & $\begin{array}{c}\text { Composição do substrato } \\
(\mathrm{kg})\end{array}$ \\
\hline 1 & 32,0 & $100 \% \mathrm{RSV}$ \\
2 & 33,8 & $5 \% \mathrm{LES}+95 \% \mathrm{RSV}$ \\
3 & 35,6 & $10 \% \mathrm{LES}+90 \% \mathrm{RSV}$ \\
\hline
\end{tabular}

Tabela 2 - Resultados das caracterizações física, química e biológica do lodo de tanque séptico

\begin{tabular}{cc}
\hline Parâmetro & Magnitude \\
\hline COT (\%ST) & 15,5 \\
NTK (\%ST) & 2,1 \\
Relação C/N & 7,4 \\
Sólidos totais voláteis (\%ST) & 28,0 \\
Teor de umidade (\%) & 77,9 \\
pH & 7,0 \\
Ovos viáveis de helminto (unidade/g de ST) & 102,4 \\
\hline
\end{tabular}

Analisando os dados apresentados na Tabela 2, observa-se que os percentuais de COT e NTK foram de $15,5 \%$ e $2,1 \%$, respectivamente; resultando numa relação $\mathrm{C} / \mathrm{N}$ de 7,42 , valor este próximo da relação considerada normal para lodos oriundos de sistemas anaeróbios de tratamento de esgoto por Ferreira et al (1999) para lodo anaeróbio que é de 9,00 .

$\mathrm{O}$ valor do $\mathrm{pH}$ se encontra entre o intervalo considerado normal para LES $(6,5$ a 7,5$)$ de acordo com Ferreira et al (1999). Andreoli et al (2001), afirmam que o lodo com pH em torno de 7,0 não interfere no processo de compostagem que, normalmente, se desenvolve muito bem com misturas de resíduos contendo o lodo sanitário.

O teor de umidade de 77,9\%, esteve abaixo dos percentuais típicos para lodos digeridos anaerobiamente, expostos em Andreoli et al (2001), que normalmente se apresenta com umidade entre $88 \%$ e $94 \%$. Este fato é decorrido da secagem natural (ao sol) do LES, antes da sua utilização no processo de codisposição.

A reduzida fração de STV encontrada, quando comparada aos dados expostos por Ferreira et al (1999), o qual afirma que o lodo digerido oriundo de processos anaeróbios deve apresentar um teor de STV dentro do intervalo de 30 a $60 \%$, refletiu a digestão anaeróbia ocorrida durante o longo tempo de permanência do lodo no interior no tanque séptico, muito embora ainda apresente um teor de matéria orgânica que permite sua utilização em processo de compostagem.
Os dados da Tabela 2, mostram números significativos de ovos viáveis de helmintos, predominando Ascaris lumbricoides, Enterobius vermiculares e Fasciola hepática. Dados sobre a concentração e prevalência de helmintos em tanques sépticos são raros, contudo, Andreoli et al (2001) afirmam que em digestores anaeróbios bem operados, é observada redução satisfatória de coliformes termotolerantes e eliminação de cistos de protozoários, enquanto os ovos de helmintos se apresentam como os mais resistentes. Portanto, no que se refere à eficiência de sanitização, os ovos viáveis de helmintos têm sido recorrentemente empregados como principais indicadores da eficiência de tal processo.

Pilotto (2004), estudando a remoção de matéria orgânica em tanques sépticos, afirma que $50 \%$ a $90 \%$ dos ovos de helminto são eliminados do esgoto, os quais seguem por sedimentação para o fundo do tanque, destacando ainda a importância da relação diretamente proporcional do nível de retenção desses ovos com o tempo de detenção hidráulica do esgoto no interior da câmara do tanque séptico. Estudo realizado por D'Castro Filho et al (2005) em lagoa de polimento da ETE. Mangueira, no Município do Recife-PE, identificou concentração média de 400 ovos de helminto/g de ST, com uma fração de ovos viáveis de 67\%, ou seja, 268 ovos/g de ST. As elevadas concentrações de ovos viáveis de helmintos normalmente verificadas em lodos sanitários, suscitam cuidados na sua remoção e no tratamento e destinação final deste resíduo. 


\section{Resíduos sólidos vegetais}

Na Tabela 3, são apresentados os parâmetros físicos e químicos dos resíduos sólidos vegetais (RV) utilizado para a preparação do substrato.

Os teores de carbono orgânico total (COT) e nitrogênio total Kjeldahl (NTK) se encontraram comparativamente abaixo dos dados disponíveis em literatura. Bidone (2001), Leite et al (2003) e Remígio (2001), observaram valores de COT e NTK de $37,0 \%$ e $2,7 \% ; 46,2 \%$ e $2,8 \%, 43,8 \%$ e $3,6 \%$, respectivamente. Muito embora, a análise da relação $\mathrm{C} / \mathrm{N}$, resultante dos dois parâmetros discutidos acima, demonstre maior homogeneidade, sobretudo quando observamos Bidone (2001) e Leite et al (2003), que encontraram relaçōes $\mathrm{C} / \mathrm{N}$ de 13,7 e 16,5, respectivamente.

A oferta de material orgânico disponível para os microrganismos, traduzida no percentual de STV, foi relativamente baixa. Apenas a nível comparativo, Leite et al (2003) e Remígio (2001), obtiveram resíduos com percentual de STV de $83,6 \%$ e 78,9\%; respectivamente.

Os valores referentes ao teor de umidade, apresentaram um resultado próximo aos dados demonstrados por Leite et al (2003) e Remígio (2001), os quais identificaram teores de $77,1 \%$ e $67,3 \%$, respectivamente. Os resíduos sólidos vegetais apresentaram, na época da coleta, características próximas da neutralidade, o mesmo resultado foi observado por Remígio (2001), que encontrou um $\mathrm{pH}$ de 6,7 nos resíduos coletados na EMPASA.

A composição física e química dos resíduos sólidos vegetais varia em função de fatores como diversidade de constituintes e diferentes proporçōes destes, aspectos de sazonalidade, vocações agrícolas regionais, dentre outros, sendo estes, provavelmente os fatores que mais influenciaram nas pequenas variaçōes observadas nos parâmetros discutidos entre os diferentes estudos demonstrados, na pesquisa aqui relatada.
Quanto à caracterização biológica (ovos viáveis de helminto/g de ST), identificou-se a concentração de 3,06 ovos/g de ST para os RSV utilizados na montagem do tratamento 1 , com a incidência de Ascaris lumbricoides na concentração de 1,75 ovos/g de ST e Fasciola hepática com 1,31 ovos/g de ST.

Nos resíduos vegetais utilizados para a montagem dos tratamentos $2 \mathrm{e}$ 3 , foram identificados 6,32 ovos/ de ST, com a incidência de $A$. lumbricoides, $F$. Hepática e Trichuris trichiura nos quantitativos de 3,13; 1,57 e 1,57 ovos/g de ST, respectivamente.

Os trabalhos que se debruçam sobre o estudo da ocorrência de ovos de helminto em alimentos são feitos quase que exclusivamente em hortaliças, se restringindo a analisar o percentual de amostras que apresentaram resultado positivo para a presença de helmintos e protozoários enteroparasitas, ou, quando muito, demonstrando os resultados em quantidade de ovos de enteroparasitas por $100 \mathrm{~g}$, não diferenciando, portanto, os ovos de helmintos dos cistos de protozoários. Isso acaba por dificultar a comparação com os resultados obtidos nessa pesquisa. No entanto, sabe-se que é bastante comum, tanto nas áreas rurais quanto urbanas dos países em desenvolvimento, devido às más condições sanitárias, a ampla disseminação de parasitoses intestinais, sendo as hortaliças citadas como importante veículo de suas estruturas infectantes (Slifkoet et al, 2000; citado por Silva et al, 2005).

A situação se agrava em algumas regiōes, como no Nordeste do Brasil, onde a escassez de água faz com que os agricultores, especialmente os horticultores, utilizem aquelas de mais fácil acesso, sem nenhum critério de qualidade, acabando por utilizar águas contaminadas na irrigação. Os efeitos dessas práticas não tardam em aparecer como no caso revelado por Lima et al (2002), que apontou a presença de ovos de helminto em alfaces comercializadas na Feira Livre Central do Município de Campina Grande-PB.

Tabela 3 - Parâmetros físicos e químicos dos RV utilizados na preparação do substrato

\begin{tabular}{ccccccc}
\hline Tratamento & \multicolumn{7}{c}{ Parâmetros } \\
& COT (\%) & NTK (\%) & Rel. C/N & STV (\%) & TU (\%) & pH \\
\hline 1 & 34,4 & 2,2 & 15,8 & 62,0 & 69,7 & 7,9 \\
2 e 3 & 36,0 & 2,1 & 17,1 & 64,9 & 71,9 & 6,9 \\
\hline
\end{tabular}

\section{Temperatura}

Nas Figuras 2, 3 e 4, observa-se a evolução temporal da temperatura média (topo, centro e base dos reatores) na massa do substrato em processo de bioestabilização aeróbia nos tratamentos 1,2 e 3 , respectivamente.

No tratamento 1 , as temperaturas médias dos reatores (Figura 2) se mantiveram apenas em níveis mesófilos - um pouco acima de $40^{\circ} \mathrm{C}$ - decaindo paulatinamente, a partir do $3^{\circ}$ ou $4^{\circ}$ dia, para valores muito próximos da temperatura ambiente, entre $20^{\circ} \mathrm{C}$ e $30^{\circ} \mathrm{C}$ até o final do processo.

Os reatores dos tratamentos 2 e 3 (Figuras 3 e 4) apresentaram tendência bastante similar, com temperaturas médias, na faixa termófila, que ficaram, já no primeiro dia da compostagem, entre $45,5^{\circ} \mathrm{C}$ no reator $\mathrm{T} 2 \mathrm{R} 1$ a $48^{\circ} \mathrm{C}$ no reator T2R2, mantendo-se neste patamar até o quinto ou sexto dia do processo, quando começaram a decair passando para a faixa mesófila, permanecendo por mais duas semanas, com valores médios variando de $40^{\circ} \mathrm{C}$ a $45^{\circ} \mathrm{C}$ entre os reatores dos tratamentos 2 e 3 , até se aproximarem da temperatura ambiente, mantendo-se, a partir de então, no intervalo médio de 20 a 30 graus, até o final do o processo. Observou-se também que os reatores que apresentaram os maiores percentuais de umidade - acima de 68\%, tiveram seus picos de temperatura média registrados no seu estrato superior (topo), ao passo que nos reatores com percentuais de umidade de $66 \%$ ou menos, registraram-se as temperaturas mais altas no estrato intermediário. Os níveis mais baixos de temperatura ocorreram no estrato inferior (base) dos reatores, devido principalmente a configuração dos reatores. A pequena duração da fase termófila foi causada, provavelmente, por fatores como: a baixa relação $\mathrm{C} / \mathrm{N}$ inicial e o alto teor de umidade, uma vez que a literatura (Haug, 1993; Kiehl, 1998; Pereira Neto, 1996) é quase unânime em apontar a relação $\mathrm{C} / \mathrm{N}$ de 25 a 30/1 e um percentual de umidade em torno dos 60\%, como valores iniciais ótimos para obtenção da maior eficiência do processo de codisposição.

A diferença de temperaturas registrada entre o Tratamento 1 e os demais foi provocada, provavelmente, pela inoculação do lodo de esgoto aos tratamentos 2 e 3 com uma massa microbiológica rica e diversa já estabe- 
lecida, produzindo uma aceleração ao processo de biodegradação da matéria orgânica (Haug, 1993).

\section{Teor de umidade (TU)}

Nas Figuras 5, 6 e 7; observa-se a evolução temporal do teor de umidade na massa do substrato em processo de bioestabilização aeróbia nos tratamentos 1,2 e 3 , respectivamente.

A umidade inicial na massa dos resíduos orgânicos (Figuras 5, 6 e 7) se apresentou acima do valor considerado ideal para o eficiente início do processo que é de 60\%, de acordo com Andreoli et al (2001); Kiehl (1998) e Pereira Neto (1996), o que dificultou a redução da umidade no primeiro mês de codisposição e proporcionou a geração de chorume. Para reduzir o teor de umidade foram adicionados $2,5 \mathrm{Kg}$ de folhas secas ao final do primeiro mês de instalação do experimento. A partir de então, a umidade foi regulada em 50\% até próximo ao término da codisposição. Segundo Jardim et al (1995), em substratos com umidade bem acima do recomendado, se instala o processo de anaerobiose com conseqüente geração de chorume.

No final do processo, o composto apresentou-se com teor de umidade dentro do intervalo considerado ideal para Lelis (1998), citado por Souza (2002) que é de 30 a 40\%, com exceção dos reatores T1R1 e T1R3, que apresentaram teores ligeiramente abaixo do recomendado: $29,0 \%$ e $29,6 \%$, respectivamente. Muito embora, níveis de umidade entre 25 - 35\% sejam considerados bons para compostos, como sugere Kiehl (1985).

\section{Potencial hidrogeniônico (pH)}

Nas Figuras 8, 9 e 10; observa-se a evolução temporal do $\mathrm{pH}$ na massa do substrato em processo de bioestabilização aeróbia nos tratamentos 1, 2 e 3 , respectivamente.

Os valores iniciais do $\mathrm{pH}$ (Figuras 8, 9 e 10) variaram de 6,9 a 8,5 , alcançando níveis de 9,0 por volta do $21^{\circ}$ dia e 11,00 em torno do $56^{\circ}$ dia, apresentando um aparente decaimento, a partir das últimas três semanas. No final do processo de codisposição, demonstrou-se tendência à estabilização, com valores de $\mathrm{pH}$ em torno de 10,00. Os autores Fialho et al (2005)

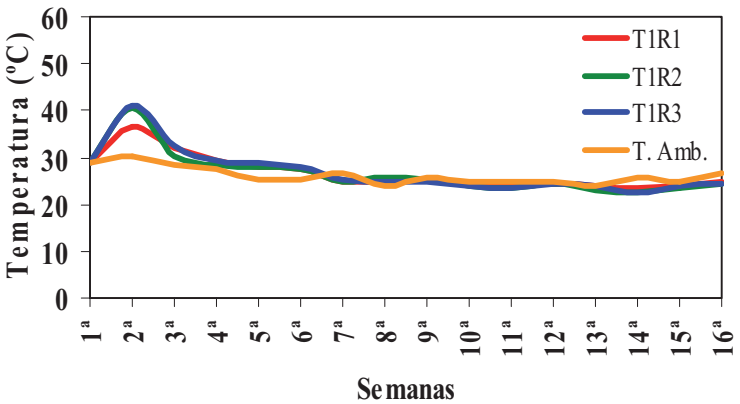

Figura 2 - Evolução temporal da temperatura média $\left({ }^{\circ} \mathrm{C}\right)$ no tratamento $I$

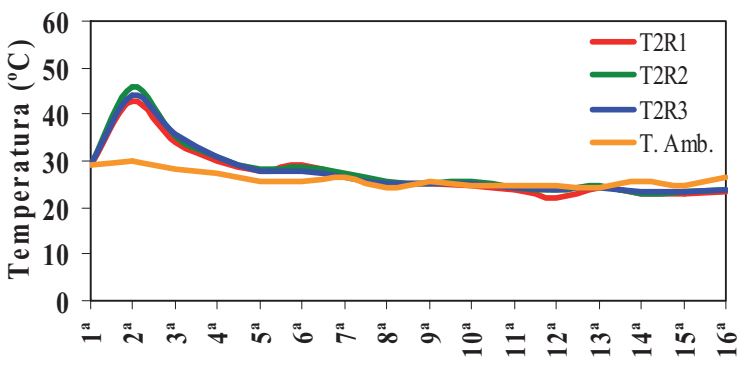

Semanas

Figura 3 - Evolução temporal da temperatura média $\left({ }^{\circ} \mathrm{C}\right)$ no tratamento 2

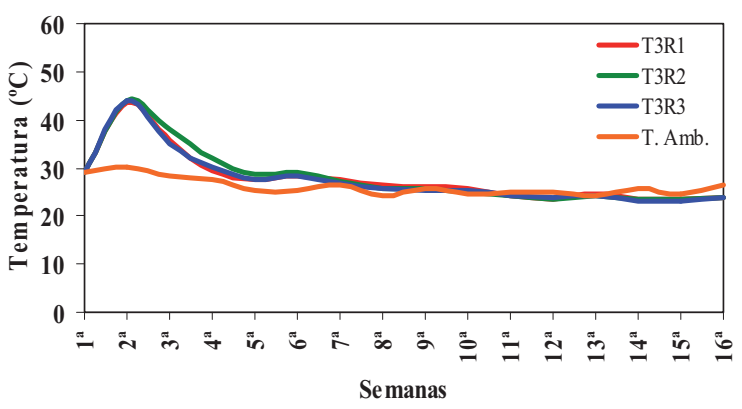

Figura 4 - Evolução temporal da temperatura média $\left({ }^{\circ} \mathrm{C}\right)$ no tratamento 3

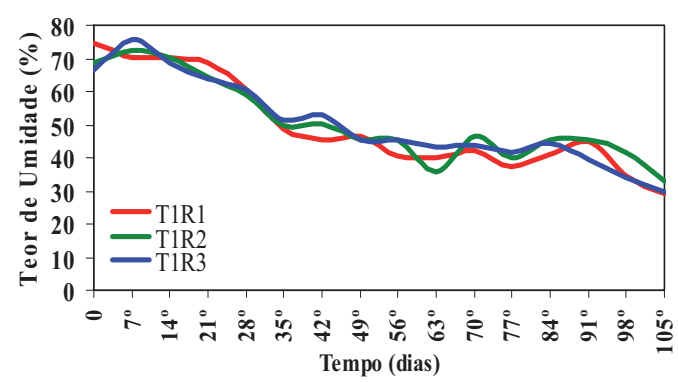

Figura 5 - Evolução temporal do teor de umidade (\%) no tratamento I 


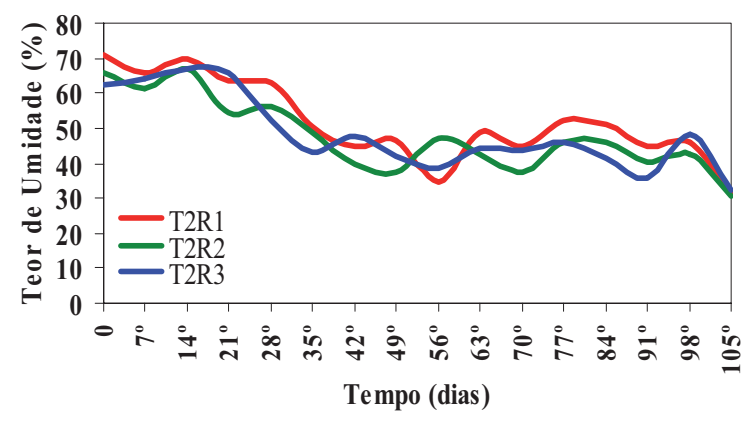

Figura 6 - Evolução temporal do teor de umidade (\%) no tratamento 2

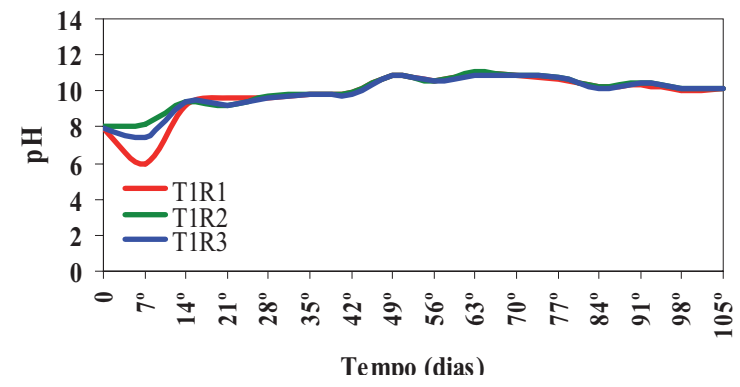

Figura 8 - Evolução temporal do potencial hidrogeniônico $(\mathrm{pH})$ no tratamento I

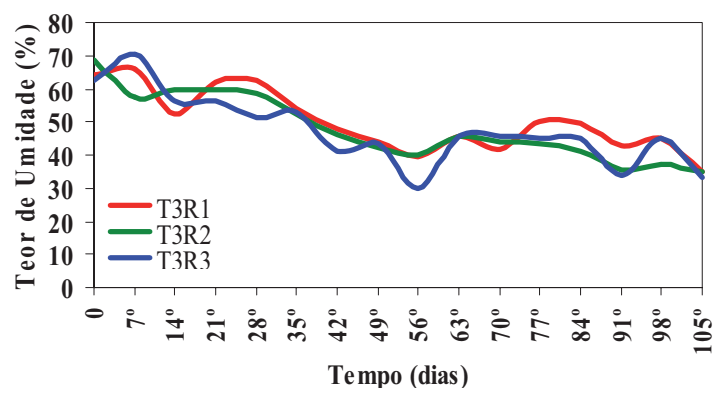

Figura 7 - Evolução temporal do teor de umidade (\%) no tratamento 3

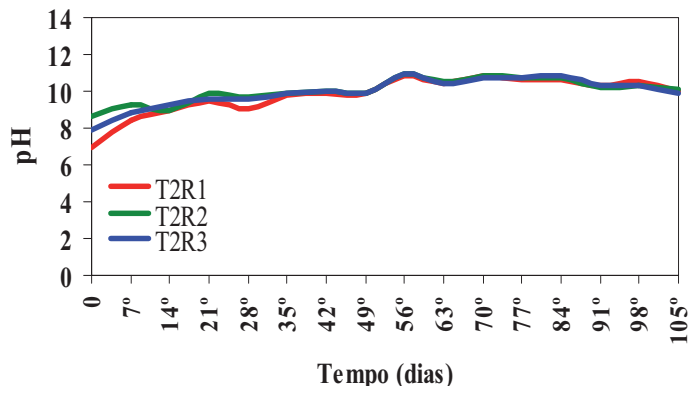

Figura 9 - Evolução temporal do potencial hidrogeniônico $(\mathrm{pH})$ no tratamento 2

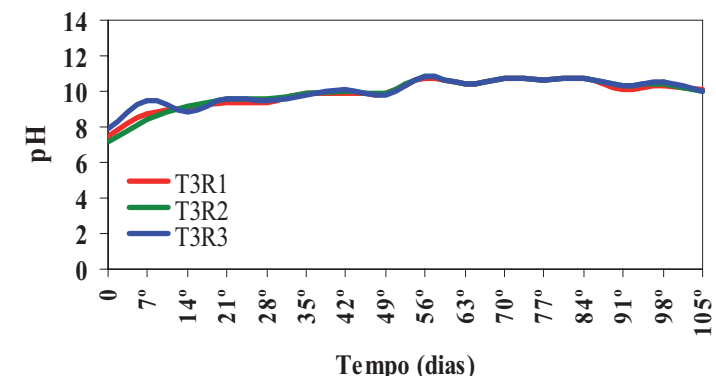

Figura 10 - Evolução temporal do potencial hidrogeniônico $(p H)$ no tratamento 3

e Pereira Neto (1996); afirmam que a compostagem conduz à formação de matéria húmica com reação alcalina, muito embora ao final do processo, esse parâmetro deva situar-se sempre na faixa de 7,0 a 8,5 .

Observou-se uma pequena queda no $\mathrm{pH}$ nas análises realizadas ao final da $1^{\text {a }}$ semana de codisposição no tratamento 1 (Figura 8), fato não observado nos demais tratamentos. Bidone (2001), esclarece que esse fenômeno é provocado pela formação de ácidos orgânicos que logo são degradados, gerando, dessa forma, um aumento do
pH. Como as análises eram semanais e o nível de degradação da matéria orgânica foi mais intenso nos tratamentos 2 e 3 , provavelmente esses ácidos tenham sido degradados antes do $7^{\circ}$ dia (quando foram feitas as análises), ocasionando um comportamento distinto entre o tratamento 1 e os demais.

\section{Sólidos totais voláteis (STV)}

Nas Figura 11, observa-se comparativamente a evolução temporal redução média dos sólidos totais voláteis na massa do substrato em processo de bioestabilização nos tratamentos 1,2 e 3

Analisando-se os dados da Figura 11 , observa-se uma tendência bastante distinta da evolução temporal na redução dos STV entre o tratamento 1 e os demais. A redução dos STV no tratamento 1 foi em média, de $31,1 \%$, ao passo que nos tratamento 2 e 3 essa redução média, ao final do período monitorado, atingiu patamares de 46,0\% e $44,0 \%$, respectivamente.

Inóculos são comumente utilizados em processos controlados de degradação da matéria orgânica, com 
o intuito muitas vezes de acelerar o processo ou mesmo facilitar a colonização dos resíduos por microrganismos capazes de realizar a degradação.

Provavelmente, a inoculação do lodo de esgoto aos tratamentos 2 e 3 com uma massa microbiológica rica e diversa já estabelecida, produzindo uma aceleração ao processo de biodegradação da matéria orgânica, como afirma Haug (1993), tenha sido fator decisivo para a ocorrência de diferença entre o tratamento 1 e os demais.

\section{Relação carbono/ nitrogênio $(\mathbf{C} / \mathbf{N})$}

Na Figura 12, 13 e 14; observa-se a evolução temporal da relação $\mathrm{C} / \mathrm{N}$ na massa do substrato em processo de bioestabilização nos tratamentos 1, 2 e 3 , respectivamente.

Teoricamente, a relação $\mathrm{C} / \mathrm{N}$ inicial ótima do substrato deve se situar em torno de $30 . \mathrm{Na}$ realidade, constata-se que ela pode variar de 20 a 70 de acordo com a maior ou menor biodegradabilidade do substrato. Tanto a falta de nitrogênio quanto a falta de carbono limitam a atividade microbiológica (Andreoli et al, 2001). Observa-se a partir das Figuras 12, 13 e 14; que a redução da relação $\mathrm{C} / \mathrm{N}$ em todos os reatores se mostrou bastante tênue, fato este ocasionado pela baixa relação $\mathrm{C} / \mathrm{N}$ inicial na massa de resíduos sólidos orgânicos utilizada. Tal tendência se deve ao fato de que, tanto os resíduos orgânicos vegetais quanto o lodo de esgoto sanitário apresentam em sua constituição altos teores de NTK. Como resultado, o processo de compostagem se desenvolveu de forma mais lenta. A relação $\mathrm{C} / \mathrm{N}$ considerada ideal ao início do processo de compostagem, de acordo com os autores Haug (1993) e Pereira Neto (1996) é 25:1 e 30:1, respectivamente.

Segundo Fialho et al (2005), valores próximos de 10 são característicos de sistemas com baixa atividade e por isso, maturados. Apesar dos valores iniciais observados para a relação $\mathrm{C} / \mathrm{N}$ não estarem dentro do intervalo ideal para início do processo de codisposição, constatou-se o bom estágio de maturação do composto produzido.

\section{Ovos viáveis de helminto}

$\mathrm{Na}$ Figura 15, 16 e 17; observa-se a evolução temporal da destruição/ina-

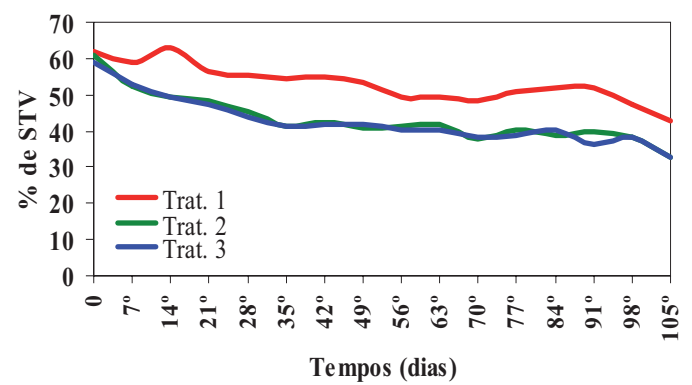

Figura I I - Comparação das evoluções temporais na redução dos sólidos totais voláteis nos tratamentos I, 2 e 3

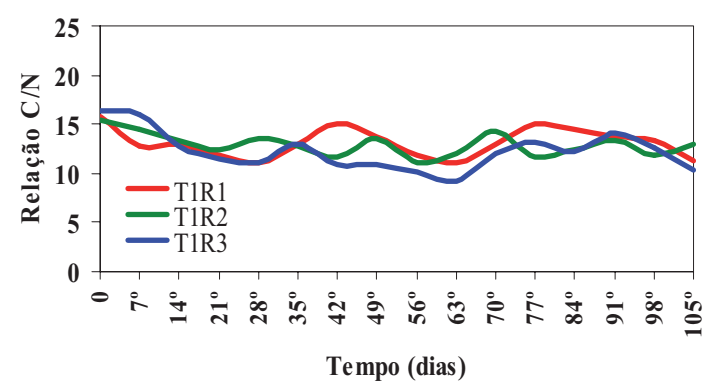

Figura I 2 - Evolução temporal da relação C/N no tratamento I

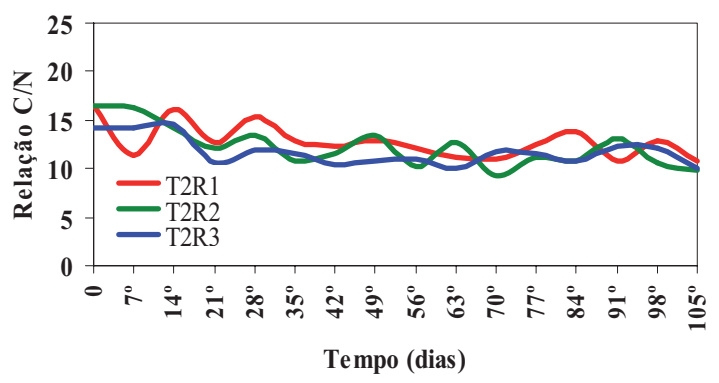

Figura I 3 - Evolução temporal da relação C/N no tratamento 2

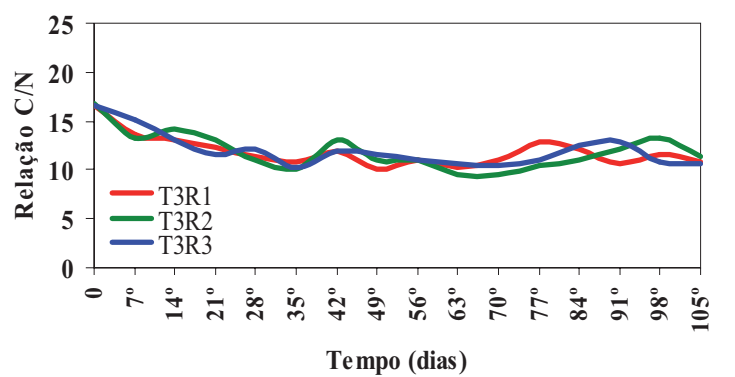

Figura I4 - Evolução temporal da relação C/N no tratamento 3 
tivação dos ovos viáveis de helminto na massa do substrato em processo de bioestabilização nos tratamentos 1,2 e 3 , respectivamente.

No tratamento 1 (Figura 15), foi observada apenas a ocorrência de Ascaris lumbricoides e Fasciola hepática, totalizando 2,57; 3,97 e 2,63 ovos/g de ST nas repetições 1, 2 e 3, respectivamente. A partir da $2^{\text {a }}$ semana não foram mais encontrados ovos viáveis de helminto nos reatores T1R1 e T1R3 até o final do processo. No tocante ao reator T1R2, observou-se a presença de $A$. lumbricoides (1,33 ovos/g de ST) no $14^{\circ}$ dia do processo, não mais sendo observado até o término da compostagem.

No tratamento 2 (Figura 16), foram quantificados 16,86; 12,46 e 12,47 ovos/g de ST nos reatores T2R1, T2R2 e T2R3, respectivamente, com ocorrência das seguintes espécies: $A$. lumbricoides, E. vermiculares, Ancylostoma $s p$. Até o $14^{\circ}$ dia do processo de codisposição houve a destruição total dos ovos de E. vermiculares e Ancylostoma $s p$. A redução média de $A$. lumbricoides ao longo da primeira semana foi de $75,36 \%$; prevalecendo neste período temperaturas de $35^{\circ}$ a $58^{\circ}$. Porém até os 98 dias do processo foi observada a presença de ovos viáveis de A. lumbricoides, variando, entre os três reatores do tratamento 2 , de 0,52 a 2,25 ovos/g de ST; a partir de então, não foram mais observados.

O tratamento 3 (Figura 17) foi iniciado com número de ovos de helmintos superior aos encontrados nos demais tratamentos (entre 23,36 e 28,47 ovos/g de ST), sendo observadas a seguintes espécies: $A$. lumbricoides, $E$. vermiculares, F. hepática, Ancylostoma sp e Clornochis sinensis.

Até o $14^{\circ}$ dia do processo de codisposição, observou-se a destruiçãao total dos ovos de E. vermiculares e $F$. hepática e Ancylostoma sp. A redução média de A. lumbricoides ao longo da primeira semana foi de $82,65 \%$; neste período prevaleceram temperaturas de $38^{\circ} \mathrm{C}$ a $54^{\circ} \mathrm{C}$. A destruição/inativação dos ovos de $A$. lumbricoides continuou de forma mais lenta no decorrer das semanas subsequientes, finalizando com a remoção de $100 \%$ dos ovos ao final do processo (105 dias de codisposição) nos reatores T3R1 e T3R2. O reator T3R3 obteve uma eficiência de remoção de $98,38 \%$, na $16^{\mathrm{a}}$ semana após a instalação do processo, permanecendo o quantitativo de 0,46 ovos/g de ST neste reator.

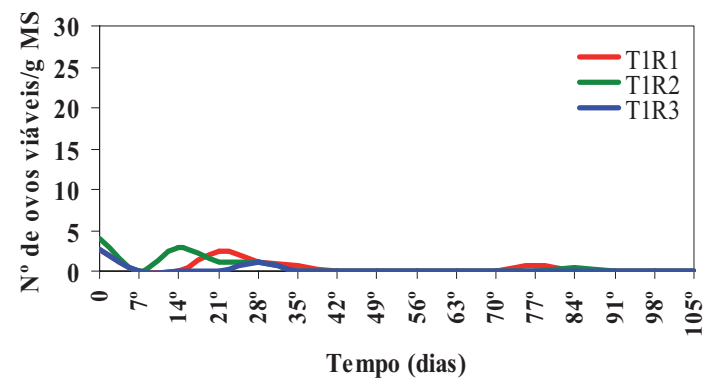

Figura I5 - Evolução temporal da destruição e/ou inativação de ovos viáveis de helminto/g.ST no tratamento I

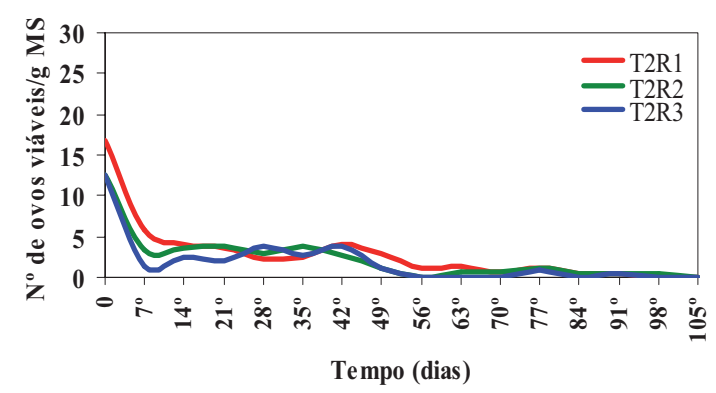

Figura 16 - Evolução temporal da destruição e/ou inativação de ovos viáveis de helminto/g.ST no tratamento 2

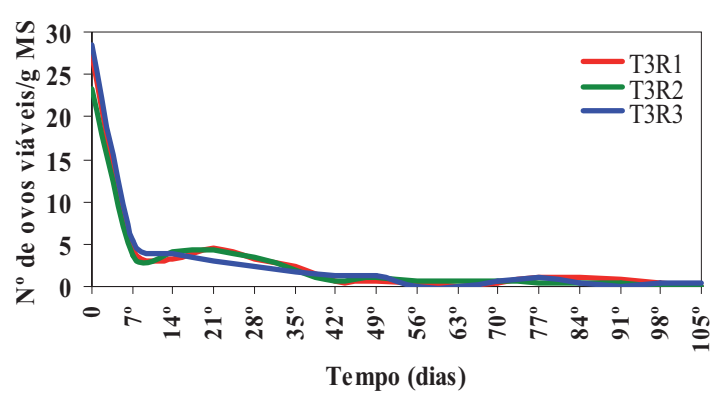
Figura I 7 - Evolução temporal da destruição e/ou inativação de ovos viáveis de helminto/g.ST no tratamento 3

De acordo com Haug (1993) e Pereira Neto (2001), os ovos de $A$. lumbricoides são muito resistentes, inclusive aos processos térmicos de higienização de resíduos orgânicos. De modo que o curto período de tempo em que ocorreram temperaturas na faixa termófila, não foi suficiente para provocar a destruição e/ou inativação dos ovos de $A$. lumbricoides, sendo, provavelmente, o $\mathrm{pH}$ que se manteve por 60 dias com valores acima de 10 , citado por Ilhenfeld et al (1999) como eficiente ferramenta para destruição e/ou inativação destes ovos, o principal responsável pela sanitização absoluta do composto, com relação a ovos viáveis de helminto. Além da destruição e/ou inativação pelo calor e por níveis de $\mathrm{pH}$ próximos ao extremo, apontados anteriormente como causas mais prováveis para a destruição e/ou inativação dos microrganismos patogênicos; Haug (1993) menciona que os patógenos são destruídos ou controlados também pelas relações ecológicas existentes na massa de compostagem, sobretudo predatismo e competição. 
Com relação ao parâmetro ovos viáveis de helminto, a Resolução CONAMA no. 375/2006 estabelece o limite de 0,25 ovos/g de ST para lodos de esgoto ou produtos derivados enquadrados na Classe $\mathrm{A}$, os quais poderão ser utilizados para quaisquer culturas, respeitadas as restriçōes previstas nos arts. 12 e 15 deste diploma legal. O adubo oriundo do reator T3R3 se enquadra como produto derivado de Classe B (menos que 10 ovos/g de ST), restringindo-se o seu uso ao cultivo de café, silvicultura, culturas para produção de fibras e óleos - com a aplicação mecanizada, em sulcos ou covas, seguida de incorporação-, respeitadas as restriçōes previstas no art. 15 e no inciso XI, do art. 18 daquela Resolução.

\section{CONCLUSÕES}

- A compostagem aeróbia conjugada mostrou ser uma alternativa viável para desinfecção e estabilização conjunta de ambos os tipos de resíduos sólidos;

- A duração limitada da fase termófila não possibilitou a destruição e/ou inativação total dos ovos viáveis de helmintos, o que demonstra que outros fatores contribuem para tal, dentre eles o pH e as relações ecológicas presentes no sistema;

- O elevado teor de umidade foi provavelmente o principal fator limitante ao prolongamento da fase termófila no processo de compostagem;

- Com base nos parâmetros monitorados, sobretudo relação $\mathrm{C} / \mathrm{N}$, STV e pH, observou-se um nível satisfatório de maturação do composto em questão.

\section{RECOMENDAÇÕES}

- Faz-se mister o estudo de diferentes configuraçốes de reatores, para se extrair o máximo de eficiência do processo de compostagem aeróbia conjugada;

- É de suma importância o desenvolvimento de novas pesquisas que enfoquem a compostagem aeróbia conjugada com percentuais mais elevados - $15 \%, 20 \%, 30 \%$ e $40 \%$ - de lodos sanitários em geral.

\section{REFERÊNCIAS}

ANDREOLI, C. V. et al. Higienização do Lodo de Esgoto. In: Resíduos sólidos do saneamento: processamento, reciclagem e disposição final/ Cleverson Vitório Andreoli (coordenador). - Rio de Janeiro: Rima, ABES, 2001.

APHA, American Public Health Association. Standard Methods for the Examination of Water and Wastewater. 20a ed. Washington D.C., 953 p. 1998.

BIDONE, F. R. A. Experiências em valorizaçāo de resíduos sólidos. In: Resíduos Sólidos provenientes de coletas especiais: reciclagem e disposição final / Francisco Ricardo Andrade Bidone (Coodernador). -- Rio de Janeiro: Rima, ABES, 2001.

BRITO Jr., A. O. S. Produção de composto usando lodo de estação de tratamento doméstico com resíduos vegetais. Dissertação (Mestrado em Engenharia Civil - Recursos Hídricos). Fortaleza/CE: UFCE. 2003.

CONSELHO NACIONAL DE MEIO AMBIENTE/CONAMA. Resolução 375/29 de Agosto de 2006. Brasília: Diário Oficial da União; 2006.

CHERNICHARO, C. A. de L. Reatores Anaeróbios. Belo Horizonte: Departamento de Engenharia Sanitária e Ambiental - Universidade Federal de Minas Gerais, 246 p. 1997.

D'CASTRO FILHO F. J. et al. Características do lodo acumulado em uma lagoa de polimento. In: $23^{\circ}$ CONGRESSO BRASILEIRO DE ENGENHARIA SANITÁRIA E AMBIENTAL. Campo Grande/ ABES, 2005.

EDLMANN, et al. Co-digestion of organic wastes and sludge from sewage treatment. In: MATA-ALVAREZ et al. Anaerobic Digestion of Solid Waste II. Water Science and Technology. vol. 41. $\mathrm{n}^{\circ}$ 3. Barcelona, Spain: IWA Publishing and The Authors, 2000.

FERREIRA, A. C.; ANDREOLI, C.V. \& LARA, A.I. Produção e características do biossólido. In: Uso e Manejo do Lodo de Esgoto na Agricultura. - Rio de Janeiro; PROSAB, Programa de Pesquisa em Saneamento Básico, 1999.

FIALHO, L. L. Monitoramento Quimico e Físico do Processo de Compostagem de Diferentes Residuos Orgânicos. Relatório Técnico. São Carlos, SP: Embrapa Instrumentação Agropecuária, 2005.

HAUG, R. T. The practical Handbook of Composting Engineering. United States of America: Lewis Publishers, 1993.

IBGE, Instituto Brasileiro de Geografia e Estatística. Pesquisa Nacional de Saneamento Básico - PNSB. IBGE: Rio de Janeiro, 2000.

ILHNFELD, R. G. K., ANDREOLI, C. V., LARA, A. I. Higienização do lodo de esgoto. In: Programa de Pesquisa em Saneamento Básico. Uso e Manejo do Lodo de Esgoto na Agricultura. - Rio de Janeiro; PROSAB, Programa de Pesquisa em Saneamento Básico, 1999.

JARDIM, N. S. et al. Lixo Municipal: manual de gerenciamento integrado. São Paulo: Instituto de Pesquisas Tecnológicas (IPT), e Compromisso Empresarial para Reciclagem (CEMPRE), 278 p,1995.

KIEHL. E. J. Fertilizantes Orgânicos. São Paulo. Ed. Agronômica Ceres, 492 p, 1985.

KIEHL. E. J. Manual de Compostagem: Maturação e qualidade do composto. Piracicaba/SP: Ed. Agronômica Ceres, 1998.

KLUBBER, H. et al. Full scale co-digestion of organic waste. In: MATA-ALVAREZ et al.
Anaerobic Digestion of Solid Waste II. Water Science and Technology. vol. 41. n⿳ 3 . Barcelona, Spain: IWA Publishing and The Authors, 2000.

LEITE, V.D. et al . Tratamento de resíduos sólidos de centrais de abastecimento e feiras livres em reator anaeróbio de batelada. Rev. bras. eng. agríc. ambient., Campina Grande, v. 7, n. 2, 2003.

LIMA, S. M. et al. Avaliação bacteriológica e parasitológica de amostras de alface (Lactuva sativa) comercializadas na cidade de Campina Grande - PB. In: $8^{\circ}$ ENCONTRO NACIONAL DE MICROBIOLOGIA AMBIENTA Rio de Janeiro: UFRJ, ANBio, PETROBRÁS, SBM. 2002.

MEYER, K. B.; MILLER, K. D.; KANESHIRO, E. S. Recovery of ascaris eggs from sludge - Journal of Parasitilogy. 64 (2), p. 380-383. 1978.

NOGUEIRA, S. F. Balanço de nutrientes e avaliação de parâmetros biogeoquímicos em áreas alagadas construidas para o tratamento de esgoto / Sandra Furlam Nogueira. Piracicaba, 2003.

PEREIRA NETO, J. T., LELIS, M. de P. N. $A$ contaminação biológica na compostagem. In: $21^{\circ}$ CONGRESSO BRASILEIRO DE ENGENHARIA SANITÁRIA E AMBIENTAL. João pessoa/ABES, 2001.

PEREIRA NETO, J.T. Manual de compostagem: processo de baixo custo. 1 ed. Belo Horizonte: UNICEF, 1996.

PILOTTO, J. S. Contribuiçôes para modelagem matemática do comportamento dos tanques sépticos para remoção de matéria orgânica. Dissertação (Mestrado em Engenharia de Recursos Hídricos e Ambiental)/Curitiba: UFPR, 2004.

REMÍGIO, A. F. N. Estudo do processo de tratamento aeróbio conjugado de resíduos orgânicos. Dissertação (Mestrado em Eng. Civil - UFPB) Campina Grande, UFPB, 2001.

SILVA, A. G da. Codisposição de Lodo de Esgoto Sanitário e Resíduos Sólidos Vegetais Dissertação (Mestrado em Desenvolvimento e Meio Ambiente) UFPB/UEPB/PRODEMA, Campina Grande, 111p. 2007.

SILVA, M. T. et al. Prevalência de Parasitas Intestinais em Crianças, com Baixos Indicadores Sócio-Econômicos, de Campina Grande (Paraíba). Revista Baiana de Saúde Pública. v. 29, n. 1, p. 121-125. 2005.

SOCCOL et al. Metodologia para Análise Parasitológica em Lodo de Esgoto. In: Manual de Métodos para Análises Microbiológicas e Parasitológicas em Reciclagem Agrícola de Lodo de Esgoto/ Cleverson Vitório Andreoli (coordenador). .Curitiba: Sanepar, 2000

SOUZA, F. C de. Avaliação da Eficiência da Compostagem Mesofilica e Termofilica. Dissertação (Mestrado em Eng. Civil - UFPB) Campina Grande: UFPB, 2002.

Endereço para correspondência:

André Gustavo da Silva

Rua Leão Diniz de Souza, 5 199,

Apt $^{\circ} 207$

54440-07 I Jaboatão dos

Guararapes - PE - Brasil

Tel: (8I) 8899-5785

E-mail:agsilva7@hotmail.com 